\title{
Suppression of Brugia malayi (sub-periodic) larval development in Aedes aegypti (Liverpool strain) fed on blood of animals immunized with microfilariae
}

\author{
K Athisaya Mary, KP Paily, SL Hoti ${ }^{+}$
}

\author{
Vector Control Research Centre, Indira Nagar, Pondicherry-605 006, India
}

\begin{abstract}
Preliminary studies were carried out to investigate the role of filarial specific antibodies, raised in an animal model against the filarial parasite, Brugia malayi (sub-periodic), in blocking their early development in an experimental mosquito host, Aedes aegypti (Liverpool strain). In order to generate filarial specific antibodies, Mongolian gerbils, Meriones unguiculatus, were immunized either with live microfilariae $(\mathrm{mf})$ of B. malayi or their homogenate. $M f$ were harvested from the peritoneal cavity of Mongolian gerbils with patent infection of $\mathrm{B}$. malayi and fed to A. aegypti along with the blood from immunized animals. Development of the parasite in infected mosquitoes was monitored until they reached infective stage larvae (L3). Fewer number of parasites developed to first stage (L1) and subsequently to $L 2$ and $L 3$ in mosquitoes fed with blood of immunized animals, when compared to those fed with blood of control animals. The results thus indicated that filarial parasite specific antibodies present in the blood of the immunized animals resulted in the reduction of number of larvae of $\mathrm{B}$. malayi developing in the mosquito host.
\end{abstract}

Key words: microfilariae - Mongolian gerbil - antibodies - mosquito host - larval development

Lymphatic filariasis caused by Wuchereria bancrofti and Brugia malayi, is a major public health problem in several tropical countries. Chemotherapy with Diethylcarbamazine citrate (DEC) is the only available tool for its control, as vector control is considered as not reliable upon exclusively for the control of filariasis (Ottesen et al. 1997). However, in order to attain the goal of filariasis elimination, it is desirable to have more than one control tool. Recently, great deal of interest has been generated in the possibility of blocking the development and transmission of parasites by vectors of diseases such as leishmaniasis (Tonui 1999), schistosomiasis (Capron et al. 1992), and Lyme disease (de Silva et al.1996). In the case of malaria, transmission-blocking vaccines have reached advanced stage of development (Kaslow 1997, Carter 2001). But there is only one such study on the antibodies regulating the development of filarial parasites (Fuhrman et al. 1992), which reports that a monoclonal antibody, MF1, could degrade the chitin containing structures of $B$. malayi $\mathrm{mf}$ in the vector mosquito. In the present paper, results of a preliminary study on the role of anti-filarial polyclonal antibodies in suppressing the development of early larval stages of the parasite in the mosquito host are presented.

Mongolian gerbils, Meriones unguiculatus, were immunized by intra-peritoneal (i/p) inoculation of microfilariae (mf) of B. malayi (sub-periodic strain). The $\mathrm{mf}$ were

${ }^{+}$Corresponding author. E-mail: slhoti@yahoo.com Received 2 May 2005

Accepted 30 May 2005 obtained by lavaging the peritoneal cavity of $B$. malayi infected Mongolian gerbils. The animals were 6-8 weeks old and the mf were harvested on 120 days post-inoculation of infective larvae to ensure that the mf were identical with respect to their age and viability. The harvested $\mathrm{mf}$ were purified by Percoll gradient centrifugation (Chandrashekar et al.1984), and were used for immunization as well as feeding the mosquitoes. Either single dose of 1000 live $\mathrm{mf}$ or their homogenate (20 $\mu \mathrm{g}$ of protein) per animal was given in sterile phosphate buffered saline (PBS, $\mathrm{pH}$ 7.4). Homogenate of mf was prepared in PBS containing a cock-tail of protease inhibitors (Maizles et al. 1999) such as, EDTA- 1M, EGTA- 1M, NEM- 1M, Pepstatin- 1 $\mathrm{mM}$, PMSF- $0.33 \mathrm{Mm}$, and TPCK- $0.1 \mathrm{M}$ at $5 \mu \mathrm{l}$ level $/ \mathrm{ml}$ of the parasite extract. The animals were immunized in duplicate for each antigen type and an equal numbers were left as controls with only PBS inoculation. Considering the ethical issues involved in the usage of laboratory animals and the duration involved, the number of animals used in this experiment was restricted to only two in each group. The antibody titre in each animal was determined two weeks after immunization by direct enzyme linked immunosorbent assay (ELISA) as per Voller et al. (1976), using $\mathrm{mf}$ homogenate antigen. Briefly, crude antigen of $B$. malayi was coated $(1 \mu \mathrm{g} / \mathrm{well})$ onto 96 well polysterene plates (Nunc-US) and incubated overnight at $4^{\circ} \mathrm{C}$. Sera samples from the experimental and control animals diluted to $1: 100$ with $0.75 \%$ bovine serum albumin (BSA) in PBS/ $\mathrm{T}$ were reacted for $2 \mathrm{~h}$ after blocking the wells with $1 \%$ BSA in PBS/T. Anti-mouse peroxidase conjugate (Sigma Chem. Co., US) was allowed to react with the antigenantibody complex, followed by the addition of $\theta$-Phenylenediamine dihydrochloride (Sigma Chem. Co., US) as substrate in phosphate citrate buffer ( $\mathrm{pH}$ 5.0). The reac- 
tion was arrested with $5 \mathrm{~N} \mathrm{H}_{2} \mathrm{SO}_{4}$ and the optical density (OD) was read at $492 \mathrm{~nm}$ in an ELISA reader (Titertek Multiscan., Lab systems).

Mf harvested freshly from the peritoneal cavity of mongolian gerbil with patent infection of $B$. malayi, as described above, were suspended in the whole blood $\left(10^{3} \mathrm{mf} / \mathrm{ml}\right)$ drawn from the immunized animals and fed to Aedes aegypti (Liverpool strain) mosquitoes employing membrane-feeding technique (Paily et al. 1995). About 80\% of the mosquitoes were found to be fully fed and they were separated from unfed and reared under standard conditions (at $26-28^{\circ} \mathrm{C}$ and $80-85 \% \mathrm{RH}$ ) for 12 days, i.e., until the $\mathrm{mf}$ ingested by them developed to infective (L3) stage. On 4th, 8th, and 12th day post feeding, 20 mosquitoes per experimental group were dissected and the number of parasites developing in them were counted and recorded.

The antibody levels (in terms of ELISA OD values) were $0.75,0.85$ and 0.032 , respectively in animals immunized with live mf, homogenate and in control animals. The data thus shows that immunization with filarial antigens, either as live $\mathrm{mf}$ or as homogenate, elicited filarial parasite specific antibody production in the experimental animals. There was no difference in the level of antibodies in animals immunized with either live mf or their homogenate.

The data on parasite development in mosquitoes on different days after feeding is presented in the Table. Ingestion of $\mathrm{mf}$ by the mosquitoes were similar in all the three groups as indicated by the uniform level of parasite burden on day 1 post-feeding. The number ranged from 12-15 in the mosquitoes fed on immunized blood and 1416 in those fed on control blood. By day 4 post-feeding, drastic reduction in the number of parasites occurred in both mosquitoes fed on blood samples of animals immunized with live $\mathrm{mf}$ as well as $\mathrm{mf}$ homogenate and it was only two parasites (L1). This initial decrease in parasite burden could be due to the specific effect of the antibody on $\mathrm{mf}$ against which the antibody was developed. However, though there was reduction in the developing stages of the parasite in the control blood fed mosquitoes, it was quite normal as the natural process of limitation of the parasite development exhibited by vector mosquitoes
(Southgate et al. 1992).

The results of the present preliminary study indicate that filarial-specific antibodies can prevent the development of larval stages of B. malayi in the mosquito host. Vector transmission-blocking antibodies have been reported with respect to other parasites causing malaria (Khurna \& Talib 1996, Carter 2001), leishmaniasis (Tonui 1999), schistosomiasis (Capron et al. 1992), and Lyme disease (de Silva et al. 1996). With respect to filarial parasites, a monoclonal antibody, MF1, has been reported to degrade the chitin containing structures in the microfilaria or in its mosquito vector during $B$. malayi development and transmission (Fuhrman et al.1992). It should be noted that although the levels of anti-filarial antibodies generated in the immunized animals were not high, it was adequate to reduce the parasite number in the mosquito host. Dissanayake et al. (1995) reported that B. malayi microfilaraemic sera samples diluted to 1:200 (working out to $0.390 \mathrm{OD}$ ) neutralized microfilarial chitinase thus preventing it from penetrating the mosquito gut. Hence, smaller concentration of anti-filarial antibodies might be sufficient to suppress the development of the $\mathrm{mf}$ in the mosquito host. Naturally, human microfilaraemic individuals are immunologically down-regulated (King \& Nutman 1991), probably due to the release of successive broods of $\mathrm{mf}$ in to the blood, and it could be the reason for the survival of the mf in the human as well as in the mosquito host that ingest them. Whereas in the present study, the immune blood used was from the animal exposed only once to $\mathrm{mf}$ and this might have caused the anti-mf activity in the mosquito host.

The present study, indicate the possibility of involvement of anti-filarial antibodies in the suppression of the development of filarial parasites. However, in order to understand the underlying mechanism that prevent parasite development, a more detailed investigation is required on the effect of compliments and antibody specificity to $\mathrm{mf}$ antigenic epitopes.

\section{ACKNOWLEDGEMENTS}

To Dr PK Das, for his encouragement, and Dr K Balaraman, for critical review of the manuscript. To Mr A Ramamoorthy, for technical support.

TABLE

Development of larval stages of Brugia malayi (sub-periodic) in Aedes aegypti (Liverpool strain) fed on blood of animals, Meriones unguiculatus, immunized with microfilariae (mf)

\begin{tabular}{|c|c|c|c|c|c|}
\hline \multirow{2}{*}{\multicolumn{2}{|c|}{$\begin{array}{l}\text { Source of blood on which } \\
\text { the mosquitoes were fed }\end{array}$}} & \multicolumn{4}{|c|}{ Number of parasites in the mosquitoes on different days after feeding ${ }^{a}$} \\
\hline & & \multirow{2}{*}{$\begin{array}{c}\begin{array}{c}\text { Mf } \\
(1 \text { st day) }\end{array} \\
12\end{array}$} & \multirow{2}{*}{$\begin{array}{c}\begin{array}{c}\text { L1 stage } \\
\text { (4th day) }\end{array} \\
2\end{array}$} & \multirow{2}{*}{$\begin{array}{c}\begin{array}{c}\text { L2 stage } \\
\text { (8th day) }\end{array} \\
1\end{array}$} & \multirow{2}{*}{$\begin{array}{c}\begin{array}{c}\text { L3 stage } \\
\text { (12th day) }\end{array} \\
\text { Nil }\end{array}$} \\
\hline $\begin{array}{l}\text { Immunised with } \\
\text { live mf }\end{array}$ & $\begin{array}{l}\text { Animal } 1 \\
\text { Animal } 2\end{array}$ & & & & \\
\hline $\begin{array}{l}\text { Immunised with } \\
\text { mf homogenate }\end{array}$ & $\begin{array}{l}\text { Animal } 1 \\
\text { Animal } 2\end{array}$ & $\begin{array}{l}15 \\
12\end{array}$ & $\begin{array}{l}2 \\
2\end{array}$ & $\begin{array}{l}2 \\
1\end{array}$ & $\begin{array}{l}1 \\
1\end{array}$ \\
\hline Control & $\begin{array}{l}\text { Animal } 1 \\
\text { Animal } 2\end{array}$ & $\begin{array}{l}16 \\
14\end{array}$ & $\begin{array}{l}14 \\
12\end{array}$ & $\begin{array}{l}12 \\
10\end{array}$ & $\begin{array}{l}11 \\
10\end{array}$ \\
\hline
\end{tabular}

$a$ : out of twenty mosquitoes dissected on the days indicated. 


\section{REFERENCES}

Capron A, Dessaint JP, Capron M, Pierce RJ 1992. Vaccine strategies against schistosomiasis. Mem Ins Oswaldo Cruz 87(Suppl. 5): 1-9.

Carter R 2001. Transmission immunity in malaria; reflections on the underlying immune mechanisms during natural infections and following artificial immunization. Vaccine 19: 2309-2314.

Chandrashekhar R, Rao UR, Rajasekariah GR, Subramanyam M 1984. Isolation of microfilariae from blood on iso-osmotic percol gradients. Indian J Med Res 79: 497-501.

de Silva AM, Telford SR, Brunet LR, Barthold SW, Fikrig E 1996. Borrelia burgdorferi ospA is an arthropod-specific transmission-blocking Lyme disease vaccine. J Exp Methods 183: 271-275.

Dissanayake S, Perler FB, Xu M, Southworth MW, Yee CK, Wang S, Dreyer G, Watawana L, Kurniawan L, Fuhrman JA, Piessens WF 1995. Differential recognition of microfilarial chitinase, a transmission blocking vaccine candidate antigen, by sera from patients with Brugian and Bancroftian filariasis. Am J Trop Med Hyg 53: 289-294.

Fuhrman JA, Lane WS, Smith RF, Piessens WF, Perler FB 1992. Transmission-blocking antibodies recognize microfilarial chitinase in brugian lymphatic filariasis. Proc Nat Aca Sciences USA 89: 1548-1552.

Kaslow DC 1997. Transmission-blocking vaccines; uses and current status of development. Int J Parasitol 27: 183-189.
Khurana SK, Talib VH 1996. Malaria vaccine. Indian J Pathol Microbiol 39: 433-441.

King CL, Nutman TB 1991. T Cell Subsets-Regulation of the Immune Response in Lymphatic Filariasis and Onchocerciasis, Elsevier, UK, A54-A58.

Maizles RM, Blaxter ML, Robertson BD, Selkirk ME 1999. Parasite antigens, parasite genes - A laboratory manual for molecular parasitology. Method 31: 103-104.

Ottesen EA, Duke BOL, Karam M, Behbehani K 1997. Strategies and tools for the control/elimination of lymphatic filariasis. Bull WHO 75: 491-503.

Paily KP, Hoti SL, Manonmani AM, Balaraman K 1995. Longevity and migration of Wuchereria bancrofti infective larvae and its distribution pattern in relation to the resting and feeding behaviour of the vector mosquito, Culex quinquefasciatus. Ann Trop Med Parasitol 89: 39-47.

Southgate BA, Bryan JH 1992. Factors affecting transmission of Wuchereria bancrofti by anopheline mosquitoes. 4. Facilitation, limitation, proportionality and their epidemiological significance. Trans R Soc Tropl Med Hyg 86: 523530 .

Tonui WK 1999. Leishmania transmission-blocking vaccines: a review. East Afr Med J: 93-96.

Voller A, Bidwell D, Bartlett A 1976. Microplate enzyme immunoassays for the immunodiagnosis of virus infections. In Manual of Clinic Immunology, American Society for Microbiology, New York, p. 506-512. 
